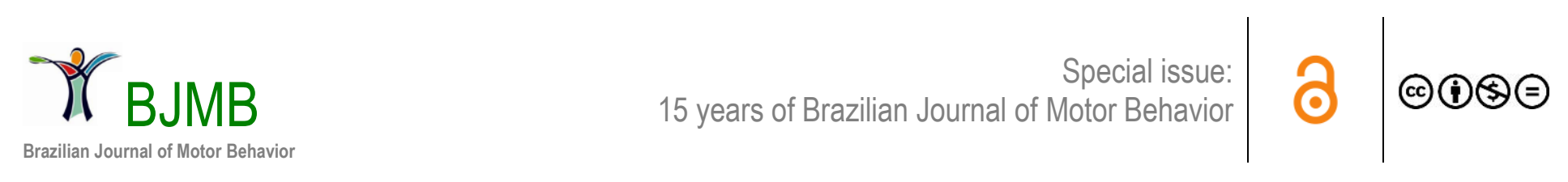

\title{
Motor development: from dynamical system approach to a neo-developmental application
}

\author{
JOSÉ A. BARELA ${ }^{1}$ \\ 1 Department of Physical Education, Institute of Biosciences, São Paulo State University, Rio Claro, SP, Brazil.
}

Correspondence to: José A. Barela. Av. 24-A, 1515, Bela Vista, Rio Claro, SP, 13506-900

email: jose.barela@unesp.br

https://doi.org/10.20338/bjmb.v15i5.282

\begin{abstract}
HIGHLIGHTS
- Motor development is influenced by many

factors, constraints, channeling changes.

- Exploration and selection allow learners to search and move beyond stable states.

- Developmental changes occur through both deterministic and environmental influences.

- Structured practice and information, provided by teachers, are critical constraints.

- Physical Education teachers are constraint manipulators inducing development.
\end{abstract}

\section{ABBREVIATIONS \\ BJMB Brazilian Journal of Motor \\ PE Physical Education}

PUBLICATION DATA

Received 01112021

Accepted 20112021

Published 01122021

\begin{abstract}
The aim of this study was to present a dynamical view of motor development and a few factors affecting the developmental course and rate of motor changes. The acquisition of motor skills involves one's exploration of many body segmental configurations, followed by the selection of those that are most useful to achieve the task demands. Exploration and selection are attained through searching and the evolution and dissolution of the stable dynamical regions of coordination modes for a given task. Development then involves an interaction between the learner and environment, dissolving relatively successful dynamics in search of even more rewarding dynamics for the new task, based upon repetitive perception-action cycles. Developmental changes can occur naturally, but can also be deterministically influenced by, for example, teachers enhancing the probability of systematic change in performance over time. This influence can be through the planned introduction of interventions and providing information that drives the learner to transition to stable modes of performance and search for new body configuration dynamics required for the new task. Teachers play an important role in guiding learners through this complex developmental journey.
\end{abstract}

KEYWORDS: Perception-action | Intrinsic dynamics | Physical education | Motor skill acquisition | Epigenetic development

\section{INTRODUCTION}

As the first editor of the Brazilian Journal of Motor Behavior (BJMB) and also as the past-president of the Brazilian Society of Motor Behavior, it is a great honor to contribute to this commemorative issue. Due to the importance of the BJMB and this celebrative atmosphere, I decided to contribute a piece on a theme that has been underlying my scientific curiosity and questioning since my early days as a researcher. Despite all my curiosity and efforts, I realized that my contribution to the motor development field has been insufficient and not entirely focused on the big picture of this challenging scientific field. Therefore, there is nothing more appropriate for this special issue than to try to fill this gap. Due to of its dimensions and complexity, preparing any paper on motor development has become a herculean task. Thus, in advance, I apologize for any simplicity and I will indicate, when appropriate, other scientific sources.

Motor development is characterized by changes over one's lifespan, showing regularity and order when looked at from above, and irregularity and disorder when looked at closely. From a dynamical view, developmental changes need to be understood as successive stable and unstable states, marked by phase shifts as one moves from one state to another. ${ }^{1}$ For example, an infant acquires an independent upright stance, stays that way

\begin{tabular}{l|l|l|l|ll}
\hline Barela & 2021 & VOL.15 & N.5 & https://doi.org/10.20338/bjmb.v15i5.282
\end{tabular}


for a certain period, and then moves on, acquiring his/her first independent steps, and so on. Moreover, although identified as an independent upright stance, each individual acquisition is characterized by many differences and unique solutions.

Despite the many advances, there are still several basic and fundamental questions that challenge motor development researchers. For instance, I have chosen two main questions to orient my scientific endeavor. The first is where does movement come from? What is the initial basis and how can we start in our developmental course? The second question is what triggers changes in our developmental course? Without a doubt, these have been important and challenging questions throughout my career.

Before presenting possible answers to these questions, I would like to elaborate on a few critical issues regarding the developmental process, to clarify the need for and importance of constraints as perception-action components. Finally, I will present a representative model of motor development over the lifespan, which will be helpful in this essay.

\section{DEVELOPMENTAL CHANGES: EXPLORATION AND SELECTION AS A PERCEPTION-ACTION SEARCHING PROCESS}

The main assumption of the dynamical view of motor development is that any change in motor behavior is influenced by several factors. ${ }^{2}$ This multi-causal view of motor development assumes that humans are complex systems composed of many elements with intense interactions among them..$^{2,3}$ Newell ${ }^{4}$ proposed that any motor action is assembled and influenced by aspects and denominated constraints from the person who is performing the action, from the environment in which each action is performed, as well as from the task that will be performed. Moreover, all the constraints involved in any motor action must be considered as none has the primacy of determining the action; rather, the action is a result of a complex relationship among all the constraints involved in that specific motor action.

Thus, the multi-causality motor development view implies that the performance of any motor action requires the individual to search and find the necessary relationship among his/her capabilities, the imposed constraints experienced by the environmental aspects, and, finally, the requirements to perform the desired action. Thelen ${ }^{5}$ suggested two underlying principles for acquiring a new task or mastering an already acquired one: exploration and selection.

The principle of exploration involves the discovery of how to organize body segments to complete a specific task in a specific environmental context. For instance, the acquisition of an independent upright stance requires that the infant figures out the body orientation, from the many that his/her motor system offers, necessary to maintain the trunk vertically and balanced over the lower limbs. The problem that the infant must solve is how to come out with something that has never been performed before. In this case, the infant will explore many possibilities for activating muscles and body positioning and select the one that best satisfies the requirements for maintaining the upright position. Therefore, this is a problem to explore in order to learn what one can perform with the organism in their environment and to select the most appropriate action in order to achieve the behavioral goal.

In the above example, the first attempts to stand upright are characterized by many difficulties, inconsistencies, falls, and a lack of refined control of movements. However, after 
a few frustrating, but crucial, tries, infants master how to coordinate and control their many body segments, employing muscle activation. Moreover, with practice, this new skill becomes consistent, stable, and performed with proficiency. Therefore, the acquisition of a new motor skill might be understood in two stages: acquisition of the new body configuration required by the task and the refinement of the movements of the new actions acquired. 3,5

The central tenet of the exploration and selection processes is that acquisition and refinement are based upon repetitions of the task, furnishing correspondent perceptionaction cycles. As an individual explores a specific set of muscle activations while performing an action, this action is accompanied by a flux of sensory consequences. According to Kelso and Engstrom, ${ }^{6}$ "... what an organism perceives is a function of how it acts, and how it acts is a function of what it perceives. The part and parcel of every action is perception, and part and parcel of every perception is action" (p. 223). The achievement or non-achievement of the action goal and the efficiency of the performed action are made available to the infant through his/her perception, i.e., through the relationship between an action and the sensory consequences of this action. Figure 1 depicts the interaction among the person, environment, and task constraints resulting in a motor skill and the inflow of sensory information triggered by the performed action. These sensory cues convey several pieces of information. First, whether or not the goal of the action is achieved. Second, if there is a need for any change in how the body segments are coordinated and controlled. Third, the action provided an important and useful influence on the environment. As previously mentioned, with repetitive trials, the flux of activity and sensory consequences modulates the new repetition, as a matter of exploring the relationship among the constraints while searching for the best outcome.

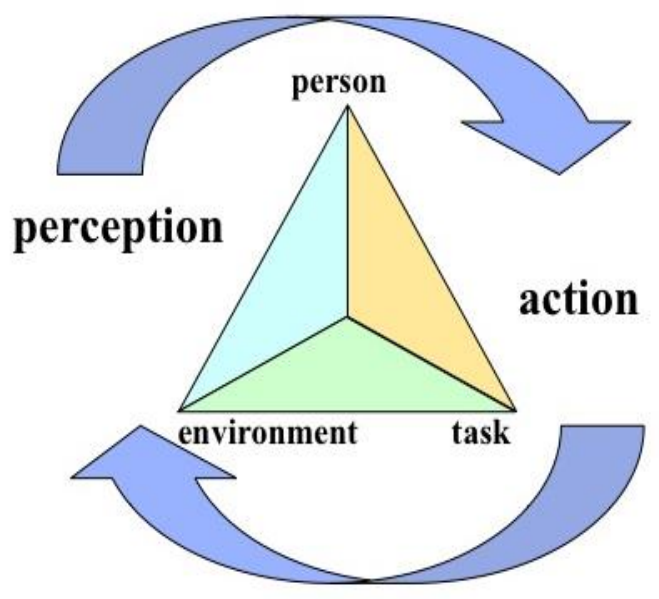

Figure 1. Representation of the relationship among constraints from the person, the environment, and the task based upon repetitive cycles of perception-action.

Considering that several factors sculpt the course and define the rate of development, and that developmental changes result from the person's interaction with the environment, we need to consider that all motor actions performed are learned. Moreover, motor skills in the repertoire are learned by active persons, with each one governing the course and rate of his or her development. Despite all the possible and diverse influences, 
the developmental course can be characterized by specific periods, as framed and represented in Figure 2, which was adapted from Barela and Avigo ${ }^{7}$ and inspired by earlier proposals..$^{8,9} \mathrm{~A}$ brief description of the main periods and issues related to this model can be found in previous studies 7,10 and the colors indicate potential representative person (red) and environmental (green) influences.

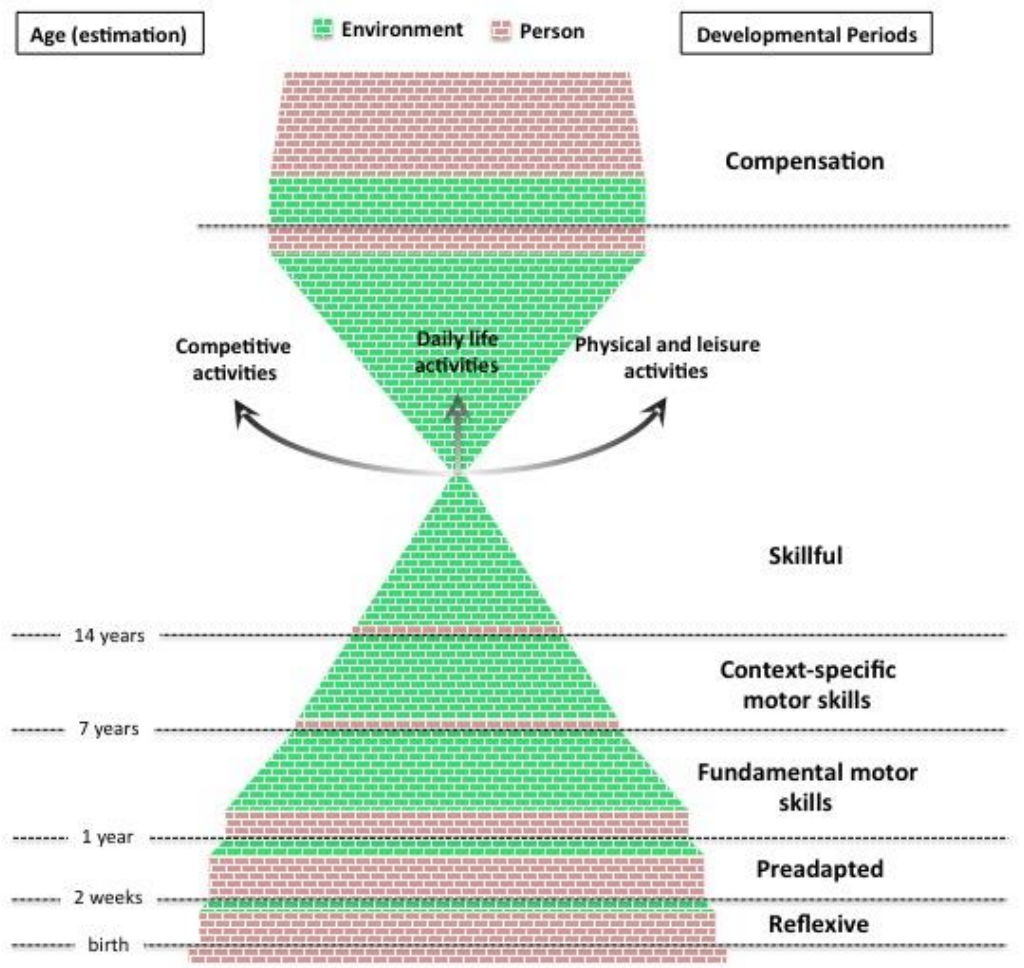

Figure 2. Representation of motor development periods throughout the lifespan. Green and brown bricks indicate estimated influences from the environment and from the person, respectively. After the building block of motor skills, acquired skills can be employed and used in different contexts (daily life, physical and leisure, and competitive activities).

The dynamical view of motor development, briefly presented previously, is quite provocative, and many previous and traditional concepts regarding developmental changes need to be re-oriented. The multi-causality assumption and the processes of exploration and selection related to skill acquisition are rather radical proposals compared to the suggestions based on a maturational view and certainly provide us with much clearer bases to understand the complex processes of motor and even human development. I argue that the dynamical view of motor development also provides answers to the two main questions that were presented previously.

\section{BIRTH KIT: NATURE AND NURTURE}

As previously mentioned, one of the driving questions is where does movement come from? In other words, what is the initial basis and how do we start on our developmental course? Continuing on from previous work, 3,11 I would like to suggest that 
due to the evolutionary process, humans already present a basic motor repertoire at birth, which allows us to launch our initial motor activities. Even before being born and despite the constrained environment of the womb, humans already perform several motor actions. After birth, motor manifestations are intensified, and several other motor actions become possible, with these movements being characterized as involuntary, spontaneous, and reflexive. ${ }^{8}$ In the model depicted in Figure 2, the first period, as in many other models, is called the reflexive period. These motor manifestations consist of reflexes (primitive, postural, and survival) that are in place at birth, and, more importantly, some can be modulated quickly after their first occurrence. For instance, some of these spontaneous or reflexive movements are initiated by specific environmental stimuli. However, their responses are not stereotypical; rather, infants can control them voluntarily after their first appearance.

These early motor manifestations have a primary survival function in infants. ${ }^{8}$ Such survival purposes can be exemplified by the sucking reflex, which makes it possible for infants to suck immediately after birth. However, after the first sucking experience, infants are capable of modulating the sucking action and controlling it quite well, interrupting and/or modulating the strength and frequency of the sucking action. In addition to the survival role, these reflexive movements also make it possible for infants to initiate a "dialog with the environment". ${ }^{8}$ Reflexive and spontaneous motor manifestations make it possible for infants to produce their first motor manifestations, acquire sensory consequences due to these movements, and gather information about what actions are possible to perform and what such actions provide to the performer.

This dialog with the environment is only possible because besides the "movement," the birth kit also provides infants with tools to evaluate the consequences of their initial actions. If infants are not able to evaluate the consequences of, for example, the sucking action, it would be dangerous and even harmful: even with something noxious, infants would continue to suck and ingest the harmful substance. On the other hand, equipped with a functional (though not yet completely developed) sensory system, infants can evaluate the substance that has been ingested by the sucking action and voluntarily modulate the sucking action.

Thus, the origin and initial basis of our developmental course come from the birth kit that we bring into this world, with both a well-structured set of actions and a well-structured system providing a flow of sensory cues as the actions occur, which is used to evaluate the consequences of these early actions: a well-defined and potential action-perception cycle, as represented in Figure 1. The so-called motor development course is only accomplished because of both movements and sensory evaluations: motor sensory development. All these initial basic capabilities, thus, provide us with the predispositions and susceptibilities, the "intrinsic dynamics", ${ }^{6}$ as we are equipped with an existing set of innate capabilities to start out, aiding our survival and interaction with the environment. Thus, nature provides us with the innate part of this process, giving us the capabilities (structure and functioning) to accommodate and assemble our behavior based on the experiences and exposure of the individual in the environment (nurture).

\section{CHANGING CONSTRAINTS: DEVELOPMENTAL FUEL}

Any action is the result of a complex relationship among all the constraints involved in that specific action. Moreover, constraints must be understood as riverbanks channeling 
water boundaries. As a birth kit, the structure and function of the motor and sensory systems channel our first motor manifestations and should be understood as the initial boundaries and intrinsic dynamics of the system. ${ }^{6}$ Although quite clever, the human birth kit, compared to other species, is quite rudimentary and infants are dependent on their parents for a long period. However, this rudimentary form allows humans to adapt to the environment. Among all animals, humans are the only species that are adaptable to most of the habitats and conditions on Earth. ${ }^{12}$ Therefore, the rudimentary nature of our initial capabilities (compared to other species) provides us with an extraordinary capacity to accommodate and adapt to different environmental conditions.

Adaptation to environmental conditions is an extraordinary characteristic, but any individual must change in order to accommodate, assimilate, and functionally interact with the environment. Such a process is accomplished by modification, expansion, and elaboration of the preexisting capabilities and potential (the birth kit) of one individual, ${ }^{6}$ which is accomplished by repetitive cycles of perception-action. ${ }^{5}$ More importantly, however, the developing individual is constantly changing; therefore, their interactions with the environment are constantly changing as well. As the constraints change (muscle strength increases, understanding improves, motivational situations arise, etc.), the individual has a new and different relationship with their surrounding environment, leading to potential further change. In this case, developmental change, as a matter of learning to accommodate and assimilate new and different individual and environmental boundaries, relies on information that is a key functional element serving to stabilize intrinsically unstable patterns of behavior. Information constitutes a functional fuel serving to destabilize previous behavior, allowing new explorations and stabilizing new behavior as infants (and any other individuals) learn how to use their bodies in the physical and social worlds to which they belong. ${ }^{13}$ Moreover, as the constraints (personal, environmental, and those related to the task) dynamically change, behaviors also must constantly change to achieve functional actions within the environment. $^{3}$

But what triggers changes in our developmental course? The answer to this question is as follows: changes in the constraints that lead to different relationships among these factors and to the acquisition of new behaviors. However, can we guarantee that the constraints will change? Nature, besides providing us with the initial motor and sensory boundaries (the "birth kit") also provides us with changing processes (growth and maturation), leading to different structures and different functioning, in a normal environment. Therefore, under normal conditions, we will change the structure and functionality, leading to different relationships with the environment. This is quite a clever, dynamical, and functional way to provide adaptability! Moreover, with the "birth kit" providing us with the basic structure and functionality, the basic course of development is most likely (if the environmental conditions are maintained with no dramatic changes) attained (order and regularity), but still sculpted in detail by individual experiences (irregularity), as suggested by the epigenetic approach.

\section{DEVELOPMENT AS SEARCHING}

Changes in behavior, such as learning, have been suggested to occur through a mixture of evolving intrinsic dynamics and deterministic influences, ${ }^{14}$ both requiring and involving a searching behavior to discover how to control our muscles to achieve a given 
task demand, and the exploration and selection processes. ${ }^{5} \mathrm{~A}$ good example of change due to evolving intrinsic dynamics is infants using touch information as they master the upright stance. ${ }^{15}$ In this study, infants were followed at different ages, contacting a surface using one hand as they stood up. Previous to independent walking, infants mostly used the contacting surface as a mechanical support. After a couple of months of walking, the infants spontaneously used this contacting surface as an informational source..$^{15}$ Such a change from mechanical to informational, as any might wonder, was not taught to the infants, but rather they discovered it by themselves. Most likely, the use of mechanical support was efficient at the beginning, providing help to the weak and not well-controlled muscles, but when the muscle capabilities were improved, the contacting surface could now provide information regarding body dynamics to be used to control muscle activation, improving postural control performance. ${ }^{15}$ The researchers only structured the environment and the task constraints, and infants searched for the best relationship with the surface based on their organismic constraints.

Similar processes could be envisioned as anyone acquires new motor tasks, especially in the first years of life. Usually, we focus on the common motor milestones; however, infants and young children increase their skill repertoire by exploring and selecting new forms of motor skills, involving mapping of information and movement dynamics to satisfy the relevant task constraints. This evolving intrinsic dynamic process is sufficient to acquire the basic motor skill forms (pre-adapted and fundamental motor skills displayed in the representative mode; Figure 2) as typical infants and children interact with environmental opportunities. There is no need for different genetic coding and instruction to allow young infants and children to deal with smartphones and other electronics devices: just let them have these novice devices at hand and they will figure out how to use them.

\section{GUIDED SEARCHING: EXPANDING THE BOUNDARIES}

In many cases, developmental changes can be implemented by searching beyond the boundaries delimited by existing constraints. There are many possible actors that may induce change (e.g., parents, peers, neighbors, friends, etc.), but I would like to draw attention to a much more important actor: the teacher, specifically the physical education (PE) teacher. One of the goals of PE teachers is to enhance and promote systematic changes in motor skills, acquisition, and performance over time. To do so, they have to promote interventions in the form of learning strategies in order to lead students to try out different and/or improved motor skill experiences. Leaning strategies imply and require changes in constraints ${ }^{14}$ in such a way that PE teachers induce students to search for a more task-rewarding dynamic. This is not a trivial issue because most likely the student is in a successful state, performing the task at a certain level with certain skillfulness, and will have to move on to temporarily unstable and less proficient task performance.

It is important to highlight that, as previously mentioned, some skills are acquired by learners as they just explore and select the required new configurations. In the first months and even years, these skills seem to appear one day in infants and children's collection of new behavior and the appearance of these basic skills in one's life leads parents and educators to think that there is no need to "teach" them, as just waiting for their appearance as a matter of maturation is enough. Certainly, this is a big mistake ${ }^{3}$ that has motivated much debate, although it is still a "ghost thought" that comes and goes. ${ }^{16}$ 
As a potential and critical constraint manipulator for inducing developmental changes, PE teachers have a difficult and challenging incumbency. First, although teachers are key actors in developmental changes, their actions focusing on development only happen indirectly. There is no on-off switch for learning and development. Learners must learn by themselves and, most of the time, with the active participation, involvement, and fruitful interaction of many factors through searching for stable dynamical coordination modes for a given task. ${ }^{14}$ Moreover, considering all the constraints that might be involved in a specific task, it is important to organize the possible learning strategies to be employed by PE teachers.

\section{PE teachers as activity promoters}

The first and imperative role of PE teachers is that they are responsible for organizing, planning, and promoting the activity that the learners will be involved in. ${ }^{3}$ Therefore, our role is to promote activities with goals related to and aimed at developmental aspects. Remember that learning and development are based upon repetitive perceptionaction cycles, and thus, teachers are the ones preparing and setting the stage for developmental activities that lead to such practice. Moreover, such a practice must be organized and structured in such a way that learners make the most of it and it is fruitful for them.

For such a herculean task, there is a need to utilize existing information. Specifically, the use of a developmental model would be helpful in organizing activities compatible with the expected developmental level of the learners. Moreover, the developmental model also constitutes an important tool for evaluating the learners' stage of development in some specific issues. If necessary, specific activities should be emphasized to promote practice and expected developmental changes toward attaining specific goals and/or guidelines. There is an increasing attempt to further understand and design strategies for promoting motor skill acquisition (for an extensive proposal, please see ${ }^{17}$ ). Evidence also shows that structured practice promotes gross motor development in young children. ${ }^{18}$

\section{PE teachers as information providers}

As already mentioned, any action provides a rich flux of sensory cues to the performer, which becomes natural information for the learner. However, the learner needs to be informed, to start with, on how to move to attain a specific action (for example, one proposed by the teacher). Due to its nature, this is called prescriptive information, as it provides information about the to-be-achieved movement kinematics as a solution to the task demands. Therefore, as part of a structured and organized practice, the PE teacher also needs to provide prescriptive information, especially for the acquisition of new motor skills, and/or draw attention to a specific aspect of the practice to be performed.

After any attempt at the teacher's proposed action/activity, the performer now has many sensory cues that can be used to inform the consequences of the action. Although the richness of these cues is important to provide a full understanding of the action's sensory consequences, it also imposes some challenges on the learner. First, there are many cues that can provide information about many aspects of an action, which might overload the learner's capabilities. Second, because of the abundance of information, the learner also faces the problem of defining and deciding the most relevant information to be used in acquiring and/or improving motor skills. Finally, despite the available cues after the action, 
the learner might not naturally pick up much of the information.

Information provided about the action dynamics produced by the learner is called feedback, which is normally and naturally available. However, because of the issues raised in the previous paragraph, in many cases, the learner might not be able to obtain and/or identify the most important and useful feedback. In this case, the PE teacher should be the feedback provider, augmenting the information available to the learner.

A major challenge for PE teachers in providing feedback is to define what augmented information should be provided to the learner. This problem is even more critical considering that we are quantity limited and can only deal with a few informative items. Thus, the teacher must decide from the many components of a to-be-achieved coordination and control solution for the specified task and inform the learners of the most important ones. Again, the proposition of a well-structured and organized practice should include the expected skill performance based on the developmental capabilities of the learners. For example, if I plan activities toward refining the running pattern, for example, I would direct the learners' attention to (a) moving their arms in opposite directions to each other, (b) moving their arms along the side of the body instead of crossing them, and (c) keeping the elbow flexed at approximately $90^{\circ}$. It would be a mental checklist, in decreasing order of expected attainment. A similar checklist would be used for other body segments.

The key issue in PE teachers assuming the role of the information provider is that the information provided will challenge, channel, and guide the learner to change the many degrees of freedom of the motor system toward the expected motor skill's specific coordination. In doing so, the PE teacher provides augmented information to the learner, expanding the information naturally available for skill acquisition and refinement as a result of the learner-environment interaction. Augmented information provided by the PE teacher in this way acts as an environmental constraint to the learner's action, varying the boundary conditions, poking and pushing learners to experience new and different perceptual-action workspaces in the realization of new task goals. This is a powerful but underestimated and even neglected role of PE teachers in the early development of our children, which requires much more of our attention.

\section{PE teachers as motivators}

Effective engagement in learning a new concept, equation, or motor skill is crucial if not determinative. There is no doubt that a motivated learner facilitates a much more effective learning process and temporally larger-scale development. Considering that any acquisition or refinement of a motor skill implies that the learner has to go beyond boundaries, exploring different perceptual-motor workspaces, such a search process has to be attained by the learner. Thus, motivation is a key issue in probing the existing skill dynamics toward new coordination and control dynamics. Definitely, such searching process might be done better and be more effective by a willing learner.

Usually, motivation in motor skill and activity learning settings is associated with the use of feedback. As suggested by Magill and Anderson, ${ }^{19}$ after practice, feedback is the most important issue in motor learning, and it is not hard to recognize its use as reinforcement and for error detection and correction. The use of just a few words ("Great, that was awesome!") provides a big push for learners to keep doing and/or maintaining the practice. A similar outcome occurs when the teacher informs the learner that their "arms were crossing a bit in front of the body" and instructs them to "try to move them along the 
body side." Thus, feedback plays an important role as reinforcement and as descriptive and prescriptive information, all important in motivating learners.

Motivation is also influenced by practice conditions that must consider and encompass a few aspects. First, a well-organized and structured activity will most likely make learners engage with more interest and effort in practice. In this case, the activity must be compatible with the learners' capabilities and, again, information from a representative model of motor development is desirable and important for such planning. Also, activities must be enjoyable and inclusive, with all participants being involved, and we are glad to be involved in promoting such initiative.$^{20}$ In all of these activities, the task demands need to be at a level that learners are able to meet. The practice must not be too easy neither too hard, which leads us to a second important aspect to be considered in proposing practice. At the same time that learners need to attain and accomplish the task demands, it has to challenge their intrinsic dynamics, pushing them toward a new task dynamic that either consolidates the new intrinsic dynamic state or moves it to a new configuration. Finally, the practice conditions must induce learners to be dynamically involved. This implies that not only must learners repeat the task, producing repetitive perception-action cycles, but also repeat it with changeable aspects to provide transfer to slightly different conditions and dynamics. Thus, we could add that practice is the most important aspect for skill acquisition, but it must be a practice that leads engaged learners to be involved and motivated to do so. Again, PE teachers play a determinative role in providing an environment that will function as an environmental demand influencing the performer to get the most out of the practice, and this is important in promoting skill development, even at a young age. ${ }^{18}$

Motivation is also influenced by the perception of competence in fulfilling task demands, ${ }^{21}$ as a lack of competence or proficiency in performing motor skills is, unfortunately, a common issue nowadays ${ }^{22}$ and it is a barrier to engagement and participation in motor activities. ${ }^{3}$ Moreover, the lack of proficiency becomes worse as one's age increases, ${ }^{22}$ indicating that practice provided to children (if any) has not been appropriated or directed to promoting motor skill development, even for those considered fundamental and used later in more complex situations. Therefore, PE teachers play an important role as developmental promoters, organizing and structuring activities, and providing information, as doing so might influence learners to improve their skill development and, more importantly, influence their motivation and engagement in physical activity.

\section{FINAL REMARKS}

Motor skill acquisition involves the exploration and selection of many possible body segment configurations through repetitive perception-action cycles. Such dynamics push learners beyond the boundaries of the stable coordination mode to a new state of dynamics required for a given task demand. Such a process occurs through a mixture of deterministic influences, such as those imposed by PE teachers. In this last case, PE teachers play the role of an important constrainer responsible for organizing structured and planned activities, providing useful information regarding skill dynamics and performance, and as motivators. These influences are decisive in promoting the developmental changes necessary and mandatory for skill acquisition. 


\section{REFERENCES}

1. Thelen E. Evolving and dissolving synergies in the development of the leg coordination. In: Wallace SA, editor. Perspective on the coordination of movement. North-Holland: Elsevier Science Publishers; 1989. p. 259-281.

2. Thelen E. Development of coordinated movement: Implications for early human development. In: Wade MG, Whiting HTA, editors. Motor development in children: Aspects of coordination and control. Boston, MA: Martin Nijhoff; 1986. p.106-119.

3. Barela JA. Fundamental motor skill proficiency is necessary for children's motor activity inclusion. Motriz. 2013;19(3):548-551.

4. Newell KM. Constraints on the development of coordination. In: Wade MG, Whiting HTA, editors. Motor development in children: Aspects of coordination and control. Boston, MA: Martin Nighoff; 1986. p. 341-360.

5. Thelen E. Motor development: A new synthesis. American Psychologist. 1995;50(2):79-95.

6. Kelso JAS, Engstrom DA. The Complementary Nature. Cambridge: The MIT Press; 2006.

7. Barela JA, Avigo EL. (2015). Movimento na infância: Combustível para o desenvolvimento. Por Escrito - Revista temática sobre a infância e a educação, São Paulo; 2015. p. 48-53.

8. Clark JE. Motor development. Encyclopedia of human behavior. 1994;3:245-255.

9. Gallahue DL, Donnelly FC. Developmental Physical Education for all children (4th ed.). Urban-Champaign, IL: Human Kinetics; 2007.

10. Barela JA. Comportamento motor: Entendendo o desenvolvimento com implicação na Educação Física. In: Pacheco Neto M, Golin CH, Taques MJ, editors. Educação Física e Esportes: Diálogos atuais. Várzea Paulista: Fontoura; 2021. p. 181-197.

11. Barela JA. Adapted physical activity in promoting infant motor development. Revista da Sobama. 2007;12(1):42-47.

12. Bronowski J. The ascent of man. London: BBC Books; 2011.

13. Thelen $E$. Grounded in the world: developmental origins of the embodied mind. Infancy. 2000;1(1):3-28.

14. Newell KM. Change in motor learning: A coordination and control perspective. Motriz. 2003;9(1):1-6.

15. Barela JA, Jeka JJ, Clark JE. The use of somatosensory information during the acquisition of independent upright stance. Infant Behavior \& Development. 1999;22(1):87-102.

16. Clark JE. On the problem of motor skill development. JOPERD. 2007;78(5):39-45.

17. Newell KM, Rovegno I. Teaching children's motor skills for team games through guided discovery: How constraints enhance learning. Frontiers in Psychology. 2021;12.724848. doi: 10.3389/fpsyg.2021.724848

18. Lemos AG, Avigo EL, Barela JA. Physical Education in kindergarten promotes fundamental motor skill development. Advances in Physical Education. 2012;2(1):17-21.

19. Magill R, Anderson D. Motor Learning and Control: Concepts and Applications. New York: McGraw Hill; 2011. 
20. Figueiredo GA, Barela AMF, Barela JA. "Joy of Moving": Um programa de jogos com o corpo e suas experiências inclusivas no Brasil. Revista Adapta. 2021;13(1):36-45.

21. Stodden DF, Goodway JD, Langerdorfer SJ, Roberton MA, Rudisill ME, Garcia C, et al. A developmental perspective on the role of motor skill competence in physical activity: An emergent relationship. Quest. 2008;60:290-306.

22. Avigo EL, Stodden DF, Silva AR, Rodrigues VB, Barela JA. Motor competence deficit in urban-area Brazilian children baed on chronological age. Brazilian Journal of Motor Behavior. 2019;13(2):52-63. doi: 10.20338/bjmb.v13i2.128

Citation: Barela JA. (2021). Motor development: from dynamical system approach to a neo-developmental application. Brazilian Journal of Motor Behavior, 15(5):321-332.

Editors: Dr Fabio Augusto Barbieri - São Paulo State University (UNESP), Bauru, SP, Brazil; Dr José Angelo Barela São Paulo State University (UNESP), Rio Claro, SP, Brazil; Dr Natalia Madalena Rinaldi - Federal University of Espírito Santo (UFES), Vitória, ES, Brazil.

Copyright: $\odot 2021$ Barela and BJMB. This is an open-access article distributed under the terms of the Creative Commons Attribution-Non Commercial-No Derivatives 4.0 International License which permits unrestricted use, distribution, and reproduction in any medium, provided the original author and source are credited.

Funding: This research did not receive any specific grant from funding agencies in the public, commercial, or not-forprofit sectors.

Competing interests: The authors have declared that no competing interests exist.

DOI: https://doi.org/10.20338/bjmb.v15i5.282 